BULLETIN Bulletin hispanique

HISPANIQUE Université Michel de Montaigne Bordeaux

114-2 | 2012

Varia

\title{
La biblioteca de un casino español de provincias a comienzos del siglo XX
}

Rafael Serrano García

\section{(2) OpenEdition}

1 Journals

Édition électronique

URL : https://journals.openedition.org/bulletinhispanique/2233

DOI : 10.4000/bulletinhispanique.2233

ISSN : $1775-3821$

Éditeur

Presses universitaires de Bordeaux

Édition imprimée

Date de publication : 31 décembre 2012

Pagination : 873-903

ISBN : 978-2-86781-855-4

ISSN : 0007-4640

Référence électronique

Rafael Serrano García, "La biblioteca de un casino español de provincias a comienzos del siglo XX », Bulletin hispanique [En ligne], 114-2 | 2012, mis en ligne le 05 janvier 2016, consulté le 28 juillet 2022.

URL : http://journals.openedition.org/bulletinhispanique/2233 ; DOI : https://doi.org/10.4000/

bulletinhispanique.2233

Tous droits réservés 


\title{
La biblioteca de un casino español de provincias a comienzos del siglo XX
}

\author{
Rafael Serrano García \\ Instituto Universitario de Historia Simancas - Universidad de Valladolid
}

Cet article propose l'étude de la bibliothèque d'un cercle espagnol, le Círculo de Recreo de Valladolid : nous y examinons attentivement le catalogue de 1903 qui contient une importante section de revues et autres publications périodiques. Cet examen montre que, en plus d'offrir évasion et distraction, ce type d'association pouvait remplir, pour une part minoritaire de ses membres, une fonction de transmission des progrès scientifiques et des nouveaux courants de pensée à l'époque du positivisme.

Mots-clés : sociabilité, loisirs, lecture.

En este artículo estudiamos la biblioteca de un casino español, el Círculo de Recreo de Valladolid, examinando con detalle el catálogo de 1903, que recoge una importante sección de revistas. Dicho examen sugiere que, junto con la evasión y el entrenimiento, estas entidades pudieron cumplir, para una minoría de socios, una función de intermediario con los avances cientificos y las nuevas corrientes de pensamiento en la era del positivismo.

Palabras claves: sociabilidad, tiempo de ocio, lectura.

In this article we study the library of a Spanish club, the Círculo de Recreo de Valladolid, accurately examining the 1903's catalogue, which assembles an important section of reviews and magazines. Such an analysis suggests that for a minority of their members, these associations could be not mere suppliers of leisure and entertainment, but also intermediaries with the scientific improvements or the new streams of consciousness at the times of Positivism.

Keywords : sociability, leisure, reading.

\section{INTRODUCCIÓN}

La institución española del Casino, nacida durante el reinado de Isabel II, siguiendo al parecer modelos extranjeros, conoció una rápida expansión de manera que, en la época de la Restauración, se había vuelto omnipresente en 
toda la geografía nacional, convirtiéndose en el tipo asociativo entonces más difundido, muy por encima de otros, como si se acomodara perfectamente bien a las necesidades en materia de relación social o a los gustos en cuanto al ocio de la sociedad de la época. No parece que entre esos gustos figurara en un primer plano la afición a la lectura, al menos de libros, aunque todo casino que se preciara contaba con una biblioteca, quizás porque los gruesos tomos encuadernados de enciclopedias, historias universales o, más aún, de revistas como la Revue des Deux Mondes, convenientemente alineados en las estanterías daban un tono de respetabilidad, de solvencia y decoro a unas entidades donde los socios se entretenían sobre todo conversando, jugando al billar o a las cartas (a veces se trataba de juegos ilícitos, prohibidos), o leyendo el periódico, no libros. Ciertamente, las escasas referencias literarias con que contamos acerca de estas bibliotecas, de Clarín, Unamuno, Arniches o Pla son poco alentadoras, y entroncan con la negativa imagen de los socios de estas entidades que nos dejó Machado en su poema "Del pasado efímero»" ${ }^{1}$ No estará de más transcribir aquí la descripción hecha por Miguel de Unamuno, referida al casino de Trujillo:

En el casino nos mostraron primero la biblioteca, una biblioteca pobrísima, cuyo catálogo podría hacer de memoria después de no haberle echado sino un vistazo. El inevitable Diccionario Enciclopédico, que sirve para dirimir las cuestiones con apuestas: la colección de Autores Españoles de Rivadeneyra, y los volúmenes de esas llamadas bibliotecas, generalmente ilustradas que se publican en Barcelona; volúmenes que tal o cual Ilustración da de regalo a sus suscriptores. Es decir, libros que no hay que escoger, pues se los dan a uno escogidos; basta decir: «envíenme los tomos todos que vayan publicados en la biblioteca o colección tal o cual». En resolución, la biblioteca del casino de Trujillo es la típica biblioteca que no se forma para lectores, sino para visitantes, para que no se diga que en el casino principal de esta población no hay una biblioteca, para que no se nos tenga por incultos. Y sobre la mesa, lo único que se lee algo; periódicos diarios y la indispensable Ilustración Española y Americana, para ver los santos. En la tal biblioteca no encontramos ni un alma; estaba completamente vacía.

En Por tierras de Portugal y de España..., p. 111.

Es obvio, sin embargo que otro tipo de círculos, los ateneos, no cabe enjuiciarlos de la misma manera, ya que en ellos la biblioteca constituía una dependencia central, fundacional, como sería el caso del Ateneo de Sevilla, provisto de un fondo bibliográfico considerable (30.000 vols. en la actualidad), logrado en parte porque ya los primeros estatutos incluyeron la obligación,

1. Unamuno se refiere a la biblioteca del casino de la localidad extremeña de Trujillo: Miguel de Unamuno, "Trujillo», Por tierras de Portugal y España / Andanzas y visiones españolas, México, Porrúa, 1983, p. 111. Clarín, por su parte, lo hace en el capítulo dedicado al Casino de Vetusta: Leopoldo Alas, "Clarín», La Regenta, Madrid, Alianza editorial, 1973, p. 109-112. Las referencias de Pla, lo son al casino de la localidad catalana de Lloret de Mar: Josep Pla, Viaje en autobuis, Barcelona, Destino, 1942. Por lo que respecta a Carlos Arniches, describe el gabinete de lectura de Villanea (un pueblo imaginario, aunque sí existe una localidad de ese nombre en Costa Rica), en La señorita de Trevélez, Madrid, Taurus, 1966, una referencia que se ha tomado de María Victoria Sotomayor Sáez, «Villanea: la aportación de Arniches a la imaginería provinciana de la literatura española», Estreno, vol. XX, nº 1, 1994, pp. 44-47. 
para cada nuevo socio, de donar un libro de su elección como cuota de entrada ${ }^{2}$. Con mayor razón, en el caso del que fue en gran medida el modelo para esta modalidad de círculos: el Ateneo de Madrid, cuyos estatutos de 1836 ordenaban la posesión de una biblioteca, que en 1873 ya contaba con 12.000 volúmenes ${ }^{3}$.

Ciertos casinos, no obstante, mostraron interés por sus bibliotecas, publicaron sus catálogos, y lo que conocemos de algunas de ellas, como esta del Círculo de Recreo de Valladolid, o la del Círculo de Calderón, en la misma ciudad ${ }^{4}$; del Salón de recreo de Burgos ${ }^{5}$, del Casino de Zaragoza ${ }^{6}$ o del Casino de Madrid 7 revela, en primer lugar, una preocupación por dotar a estas instituciones de un fondo literario abundante y variado, o la presencia de un surtido de revistas ciertamente importante, entre las que hay constancia de numerosas publicaciones extranjeras. Figuran, además, obras de autores que desdicen de la imagen de frivolidad, de apatía intelectual, de acatamiento acrítico del orden establecido en lo que respecta a la religión, a la política, a la organización social que se vincula a estas sociedades de recreo. Debe de tenerse en cuenta por otra parte que algunas de estas bibliotecas podían rivalizar con éxito con las provinciales, constituidas, como los museos de ese nivel, con fondos literarios de los conventos desamortizados: es significativo que Ramón Alvarez de la Braña afirmara que esta biblioteca del casino vallisoletano destinaba más dinero a la adquisición de libros que la que él mismo dirigía, la Biblioteca provincial de León ${ }^{8}$. Nos ha parecido por ello, que el estudio de una de estas bibliotecas, en

2. Enrique Barrero González «La biblioteca del Ateneo de Sevilla», Mi biblioteca. La revista del mundo bibliotecario, 20, 2010, pp. 92-96.

3. Federico Carlos Sáinz de Robles, «Breve historia del la biblioteca del Ateneo de

Madrid», Anales del Instituto de estudios madrileños, 7, 1971, p. 396. Un lector asiduo a dicha biblioteca era Miguel Rivera: Armando Palacio Valdés, Riverita, en Obras Completas, T. I, Madrid Aguilar, 1945, p. 269, pról. de Luis Astrana Marín.

4. Catálogo de las obras existentes en la Biblioteca en abril de 1893, Valladolid, Círculo de Calderón de la Barca, 1893, Impta. Hijos de J. Pastor.

5. Catálogo de la biblioteca de la Sociedad Salón de Recreo de Burgos, Burgos, Imprenta J. Sáiz y Compañía, 1916. Este catálogo fue obra de Natalio López Bravo.

6. Cabe remitir a María Remedios Moralejo Álvarez y María Dolores Pedraza Prades, La biblioteca del Casino de Zaragoza, Zaragoza, Diputación Provincial, Institución «Fernando el Católico», 1982. Existe un Catálogo de la biblioteca del Casino de Zaragoza, Zaragoza, Imprenta de ediciones aragonesas, 1916.

7. Una descripción muy sumaria en el artículo (sin firma), «La biblioteca del Casino de Madrid», en Encuadernación de arte. Revista para el fomento de la encuadernación, 19 (2002), pp. 35-40. Dicha biblioteca, de estilo neogótico, se inspiró en parte en la del Senado: María Zozaya Montes, El Casino de Madrid: ocio, sociabilidad, identidad y representación social, Madrid, Universidad Complutense de Madrid, Tesis doctoral, p. 740. Otra biblioteca de considerable interés arquitectónico y con elementos decorativos muy originales es la del Casino de Murcia: Francisco Javier Pérez Rojas, Casinos de la región murciana. Un estudio preliminar (1850-1920), Valencia, Colegio oficial de arquitectos de Valencia y Murcia / Fernando Torres Editor, 1980, pp. 52-53.

8. Ramón Álvarez de la Braña, Catálogos de la Biblioteca provincial de León, León, Imprenta de Rafael Garzo e hijos, 1875, p. XVIII. Es cierto que dicha biblioteca se benefició de donaciones importantes, como la efectuada por el clérigo y catedrático krausista, Fernando de Castro, que la 
la etapa en que seguramente estas entidades vivieron sus días más brillantes, la de la Restauración borbónica, puede revestir interés, más si se pone en relación con la concreta sociedad recreativa que la albergaba: este Círculo de Recreo de Valladolid, con sus socios y con la ciudad en la que se asentaba (y continúa haciéndolo). Procuraremos no perder de vista, sin embargo, que la finalidad de este centro, en una declaración que repiten los sucesivos reglamentos de que se dotó, era la de "proporcionar a los socios las distracciones y el recreo de una buena sociedad " ${ }^{9}$, una orientación que se percibe también en la propia biblioteca que no cabe asociar, ni por sus fondos ni por el uso que, presumiblemente hacían los socios de ella, a unos propósitos educativos o de formación de la ciudadanía.

El hecho de contar con el Indice de los libros de su biblioteca, confeccionado por Leandro Mariscal, vicebibliotecario en la fecha en que aquel fue publicado, 1903, y de disponer de los libros de actas, tanto de la junta directiva como de las juntas generales del Círculo, donde las referencias a la biblioteca y al gabinete de lectura son relativamente abundantes, anima a acometer este estudio, poniéndolo en relación con la tipología de los socios que pertenecían a la Sociedad, con las orientaciones de la burguesía local en aquella época, concretadas en la defensa del proteccionismo triguero, o con algunas de las características de una ciudad que distaba de tener un perfil industrial, como el ser un enclave comercial, administrativo y de servicios importante en el espacio castellano-leonés, lo que explicaría el peso de otros segmentos de esa burguesía o clase media cuyos miembros varones nutrían los registros de socios de la entidad, y cuyas aficiones y gustos en materia literaria influirían seguramente en la composición de esta biblioteca.

\section{Noticias sobre el CírCULO DE RECREO y SObre la CONSTitución} DEL GABINETE DE LECTURA Y LA BIBLIOTECA

La misma se alojaba en una entidad, el Círculo de Valladolid (más tarde, Círculo de Recreo de Valladolid), creada en esta ciudad castellana el 20 de junio de 1844 por un pequeño grupo de miembros de la burguesía local relacionados con el comercio, la industria, la Desamortización y que se emplazó en el solar resultante de la demolición del convento de San Francisco, pronto convertido en el área predilecta de habitación de dicha burguesía para lo que restaba de centuria ${ }^{10}$. A pesar de la competencia de otras entidades recreativas, este Círculo se convirtió en la referencia principal de la sociabilidad elitista en el Valladolid de la Restauración, en un espacio cerrado para el resto de los vallisoletanos,

dotó «con 600 volúmenes bien empastados».

9. Reglamento del Círculo de Valladolid, Valladolid, Imprenta de la Sra. Viuda de Aparicio, 1844 , p. 3 .

10. Cabe remitir a Philippe Lavastre, Valladolid et ses élites. Les illusions d'une capitale régionale (1840-1900), Madrid, Casa de Velázquez, 2007. 
pero clausurado también desde una perspectiva de género, pues se trataba de una sociedad exclusivamente masculina. Como decía, quizás con un punto de exageración, el escritor Francisco de Cossío, quien llegaría a ser presidente de la entidad en la década de 1930:

El CÍRCULO de RECREO era el lugar que marcaba de una manera precisa las jerarquías. La ciudad parecía dividida en dos sectores, el del Círculo de Recreo, muy reducido, y el otro, en el que toda promiscuidad era posible y toda mezcla estaba justificada. El hombre de la calle, cuando pasaba por la acera donde se encontraba el Círculo, se sentía un poco intimidado, porque de aquellos salones cuyas arańas monumentales a través de las vidrieras taladraban la niebla de las noches invernizas, partían los dictados influyentes para la vida de la ciudad ${ }^{11}$.

El Círculo ha proseguido su marcha hasta la actualidad, ocupando un hermoso edificio de tipo francés, con tejados «a la Mansard» ${ }^{12}$, en la calle de Duque de la Victoria, y ha pasado por diversas vicisitudes: de declive y pérdida de socios en los años 20 y 30 de la pasada centuria, de recuperación y prosperidad durante la Dictadura franquista, tras una importante reforma en su reglamento aprobada en 1940. La Sociedad, sin embargo, no supo evolucionar adaptándose a los cambios sociales y culturales del desarrollismo propios del último franquismo, y dependió crecientemente de los ingresos obtenidos de la práctica, en régimen de tolerancia, de juegos prohibidos. De ese modo, cuando, en plena Transición a la democracia, la llamada sala del crimen hubo de ser clausurada en 1978 tras la denuncia aparecida en un periódico, el Círculo entró en un declive que parece irremediable, sufriendo una pérdida progresiva de socios, y se ha convertido en una especie de club de la tercera edad.

La dotación de un fondo bibliográfico, de una biblioteca inicial se produjo ya durante la época isabelina, pese a que en el primer reglamento del Círculo no se contemplaba ese servicio, y sí tan solo un gabinete de lectura. Tampoco existía, dentro de la directiva, el cargo de bibliotecario, ya que este puesto aparece a partir de 1856. Es significativa la consideración que, quien lo desempeñaba en 1858, Narciso Beamud, les hizo a sus compañeros de directiva, acerca de la necesidad de continuar el estante del gabinete de lectura «si los libros se habían de conservar» ${ }^{13}$.

El gabinete de lectura de la etapa inicial, incorporando ya algunos estantes para libros, debió de ser una dependencia bastante frecuentada, y prueba de ello es que a finales de 1863 se acordara que el mozo destinado allí fuera de

11. Francisco de Cossío, Elvira Coloma o al morir un siglo, Valladolid, Junta de Castilla y León, 1994, p. 57.

12. Como explicaba en su memoria de abril de 1900 el arquitecto, Emilio Baeza: Archivo Municipal de Valladolid, C. 278-16: Petición de licencia por Antonio Pintó para construir un edificio destinado a Casino, Calle de Duque de la Victoria. Puede verse asimismo: María Antonia Virgili Blanquet, Desarrollo urbanistico y arquitectónico de Valladolid (1851-1936), Valladolid, Ayuntamiento de Valladolid, 1979, pp. 212-215.

13. Archivo del Círculo de Recreo de Valladolid (en adelante ACRV), Libro de actas de la junta directiva, 1854-1866, s. de 26-X-1858. 
permanencia fija en ese lugar, para un mejor servicio de los socios ${ }^{14}$. Como los otros salones del Círculo, la estancia llevaba divanes de gutapercha; el tablero de las mesas iba cubierto de terciopelo de Utrecht y en 1866, en relación con una importante compra de libros, se dispuso adquirir dos estanterías de roble tallado al objeto "de formar en ellas una biblioteca recreativa» ${ }^{15}$. En las paredes se colocaron en 1861 mapas para ilustración de los socios.

Debido al incremento de los volúmenes impresos, hubo que proceder a encargar nuevas estanterías, como la contratada en 1882 con el sr. Almejún, por un importe de 21.000 rs. También en 1895, la directiva encargaría al bibliotecario Arrimadas para que, en unión con Santiago Alba, muy joven por entonces, y que ocupaba el puesto de vicebibliotecario construyera nuevas librerías para la «biblioteca alta», probablemente otra dependencia separada de la primitiva, y donde se leían las revistas ${ }^{16}$. En cualquier modo, el trabajo que daban la biblioteca y el gabinete de lectura debía de ser importante, y en 1882 se acordó darle una gratificación mensual al mozo encargado de este servicio que le compensara en parte del hecho de que no podía recibir propinas, a diferencia de lo que ocurría con los mozos que atendían en el salón ${ }^{17}$.

Junto con la incorporación de nuevas estanterías, durante el periodo restaurador se mejoró la iluminación, primero por medio de mecheros de gas y, más tarde, de lámparas eléctricas. Pese a estas mejoras, la sala no se encontraba bien alumbrada, a juicio de los usuarios, quienes se quejaron también de que las mesas de lectura eran pequeñas para el extraordinario número de personas que acudían a la biblioteca ${ }^{18}$. Otras novedades consistieron en la colocación de cuatro cuadros, dos en el salón de lectura y otros dos en la Biblioteca, para dar cuenta de los libros adquiridos y donados, así como hacer papeletas para la petición de $\operatorname{libros}^{19}$. En la Junta General de diciembre de 1918, en fin, el presidente en funciones, C. Mantilla, informaba de la completa y científica catalogación del fondo bibliográfico que se había llevado a término y que constaba de tres partes: 1) Catálogo sistemático de materias, con arreglo a la clasificación bibliográfica de Brunet $^{20}$; 2) Catálogo alfabético de autores y 3) Inventario general o catálogo topográfico. Para llevar a cabo estos trabajos de catalogación se habían hecho algunas reformas, como el arreglo de la mesa Indice, adquiriendo papeletas adaptables a aquella ${ }^{21}$.

Sólo muy de vez en cuando las actas informan de las adquisiciones efectuadas, tanto de libros como de periódicos y revistas (en este caso, de las altas y bajas).

14. Ibidem, s. de 7-XII-1863.

15. Ibidem, s. de 6-IV-1866.

16. ACRV, Libro de actas de la Junta directiva, 1893-1906, ss. de 25-III-1895 y 22-XII1896.

17. ACRV, Libro de actas de la Junta directiva, 1866-1888, s. de 22-XII-1882.

18. ACRV, Libro de actas de la Junta directiva, 1906-1918, s. de 9-II-1909.

19. Ibidem, s. de 3-I-1914

20. El sistema ideado por Jacques-Charles Brunet y desarrollado en su Manuel du Libraire et de l'amateur de livres, publicado en 1810, se considera una de las primeras clasificaciones científicas en la historia del libro.

21. ACRV, Libro de actas de las Juntas Generales, 1912-1961, s. de 30-XII-1918. 
Durante la etapa inicial de la Sociedad se mencionan expresamente, entre las obras adquiridas: La Revolución de España, del Conde de Toreno, Causas célebres o Historia de la villa de Madrid, la Guía de forasteros. En 1866 se llevaron a cabo compras importantes respondiendo a la idea, constante en la Junta, «de elevar la Biblioteca a la altura que debe tener la de una sociedad como ésta», aprobándose la de todas las obras de Javier de Burgos, Duque de Rivas, Pacheco, Balmes o Donoso Cortés, los Opúsculos, de Bravo Murillo, El paraiso perdido, de Milton, la Biblia de Scio, El espiritu del siglo, de Martínez de la Rosa, al lado de otros títulos o autores más difícilmente identificables por su defectuosa transcripción. Parece existir detrás de estas decisiones un anhelo de respetabilidad, debido al lustre que daría el contar con una selecta y cuidada biblioteca, pero también de permanencia, de estabilidad, al contribuir a la formación de «lo que no se destruye y, en cambio, adquiere cada día más valor e importancia ${ }^{22}$. Frente a lo efímero del periódico diario, el alineamiento en los estantes del gabinete de lectura de grandes tomos encuadernados pertenecientes a autores muy reconocidos ayudaba sin duda a proyectar entre los propios socios esa imagen de entidad respetable, por culta, y duradera.

En la primera parte de la Restauración, hasta 1900, entre las adquisiciones de importancia estaría la Enciclopedia de Melladoo ${ }^{23}$, el Diario de Sesiones del Congreso Nacional Mercantil, el Cronicón científico popular, de Emilio Huelín, la Bibliothèque Scientifique Internationale ${ }^{24}$, el Diccionario de legislación y jurisprudencia de Alcubilla, así como el Diccionario [enciclopédico] HispanoAmericano, tan interesante y que contaba con una nutrida presencia de intelectuales krausoinstitucionistas, a propuesta, en este último caso, de Santiago Alba $^{25}$. Con posterioridad cabe mencionar la compra de: el Estudio critico en homenaje tributado a la obra del ingenioso hidalgo D. Quijote de la Mancha, de D. Isidoro Lafuente Sanz, el Estudio histórico del cuerpo de ingenieros militares, la Historia del arte, de Michel, entre otras. En alguna ocasión se mencionan compras efectuadas a demanda de los socios: sería el caso de las obras, Elements de botanique y Traité de botanique del francés Philippe Van Tieghem, o de la obra de medicina interna de Molz y Staehelin ${ }^{26}$, lo que permite vislumbrar otras funciones de la biblioteca que sobrepasaban lo meramente recreativo, y la utilidad que podía rendir a determinados colectivos profesionales, en este caso, farmacéuticos y médicos.

22. ACRV, Libro de actas de la junta directiva, 1854-1866, s. de 6-IV-1866.

23. El título completo sería el de Enciclopedia moderna. Diccionario universal de literatura, ciencias, artes, agricultura, industria y comercio, publicada por Francisco de P. Mellado, Madrid, Establecimiento tipográfico de Mellado, 1851-1855.

24. ACRV, Libro de actas de la Junta directiva, 1866-1888, ss. de 24-III y 14-IV-1887.

25. En la biblioteca figuraba también, aún cuando su adquisición no está registrada en las actas, el Grand dictionnaire universel du XIXe siècle, de Pierre Larousse, una de las obras que mejor condensan la vertiente librepensadora y laica de la cultura francesa y europea de dicha centuria. Una valoración exhaustiva de su importancia en Jean-Yves Mollier y Pascal Ory, Pierre Larousse et son temps, Paris, Larousse, 1995.

26. ACRV, Libro de actas de la Junta directiva, 1906-1918, s. de 9-X-1916. 
En cambio, se suspendió la suscripción -puesto que la compra de muchas de estas colecciones se hacía de esta manera-, a la colección Monumentos históricos de España, así como de otras publicaciones de la misma índole en los casos en que la Sociedad no estuviera comprometida a mantenerla hasta el final de su publicación ${ }^{27}$. Lo cual provocaría, exactamente un año después, una reclamación hecha por José Dorregaray, desde Madrid, en torno a la continuidad de la suscripción a otras colecciones: El Museo español de antigüedades, y Monumentos arquitectónicos, decidiendo la directiva buscar un acuerdo satisfactorio para ambas partes: suspenderla, pero una vez pagados los tomos y entregas hasta el 30 de junio de $1878^{28}$. Es de suponer que los editores de estas costosas e imponentes colecciones literarias veían como potenciales clientes, muy a tener en cuenta, a los círculos de instrucción y recreo aunque, debido a que apenas se ha conservado la correspondencia en el archivo del Círculo, es muy difícil documentar las gestiones concretas que pudieron hacer. Como dato concreto se aportará el de que, en 1879, el representante de una casa extranjera le ofreció al bibliotecario la venta de varias obras de lujo, pero no se consignan cuáles fueran ni el nombre de la editorial y del agente.

Otro aspecto a señalar, en una consideración de conjunto de esta biblioteca, es el de la localización de los fondos, repartidos en tres dependencias (el gabinete de lectura, la biblioteca y la sala de juntas), pero sobre todo en la Biblioteca propiamente dicha, donde se alojaban, como es lógico, la mayor parte de los libros, incluyendo casi todos los de la Bibliothèque Scientifique. Algunas obras, no obstante, se colocaron en el gabinete de lectura, y puede ser significativo que prácticamente todos los libros de derecho, tratados, códigos, repertorios de jurisprudencia tuvieran esa localización, quizás porque allí eran más accesibles y manejables que en la biblioteca donde cabe pensar que los libros estarían colocados en armarios cerrados con llave (como ocurre en la biblioteca actual), tal y como relata Clarín en La Regenta. También se encontraban allí algunas enciclopedias y todos los diccionarios, cuya autoridad era reclamada en las discusiones entabladas en las tertulias ${ }^{29}$. Otra disciplina en la que la totalidad de las obras que poseía el Círculo se colocaron en el gabinete de lectura era la medicina lo que parece indicar que tanto en este caso, como en el de los profesionales del derecho, el manejo de estas obras era frecuente. Es otra prueba de la importancia de juristas y médicos en la ciudad y en el propio casino.

Por último, y respecto de los directivos que desempeñaron el puesto de bibliotecario y de vicebibliotecario, se pueden aportar algunos datos, como la ocupación del mismo por políticos destacados en la esfera local o estatal,

27. ACRV, Libro de actas de la Junta directiva, 1866-1888, s. de 8-V-1877.

28. Ibidem, s. de 25-V-1878.

29. Cansinos-Assens, evocando la sala de redacción de La Correspondencia de España se refería a que en la cabecera de la misma había «dos grandes estantes de caoba, con libros, entre ellos las enciclopedias de Montaner y Simón y Larousse, indispensables para resolver dudas del momento. Podía sentirse uno allí como en un Ateneo o un Círculo»: Rafael Cansinos-Asséns, La novela de un literato (Hombres-ideas-efemérides-anécdotas...). T.1(1882-1914), Madrid, Alianza Editorial, 1982, p. 249, edic. preparada por Rafael M. Cansinos. 
tales como Francisco Zarandona, Cesáreo Aguirre, Sabino Herrero o el mismo Santiago Alba, por varios catedráticos de universidad, como Nicolás de la Fuente Arrimadas, César Mantilla Ortiz, Leopoldo Morales o Andrés Torre Ruiz o de escritores, archiveros o eruditos locales de relieve, como Federico Santander y Francisco de Cossío, ambos directores del Norte de Castilla, cuyo propietario era Santiago Alba, como Narciso Alonso Cortés, catedrático de instituto y académico, o como Alfredo Basanta de la Riva, Mariano Alcocer y Saturnino Rivera Manescau. En general, parece tratarse de personas activas en sus respectivas profesiones, y no como el personaje de Pedro Álvarez, en La calle de Valverde, bibliotecario del Casino (supuestamente de Madrid), que confesaba que lo único que había procurado en la vida era no hacer nada ${ }^{30}$.

La biblioteca se nutrió de donaciones, pero, sobre todo de compras, aunque no es posible determinar, salvo para algunos momentos aislados, las sumas que invirtió la Sociedad en este interesante servicio. En 1846, a partir de las cuentas de ese año, se sabe que se invirtieron 3.704,2 rs. en la suscripción a periódicos (sólo existía entonces el gabinete de lectura), lo que supuso el 5,6 \% de sus gastos anuales. Y mucho después en 1906, consta un acuerdo de la directiva para destinar mensualmente 150 pts, a «adquirir todo lo más moderno y digno de figurar en la Biblioteca», a juicio del responsable de la misma ${ }^{31}$.

Hubo bibliotecarios, por otro lado, como Teófilo Bayón, en 1876, que hicieron gestiones con las Reales Academias, para lograr el envío sin coste de los discursos de ingreso de sus miembros electos ${ }^{32}$. Y, por supuesto, también hubo socios o exsocios que donaron obras suyas, como el militar José Almirante (Diccionario militar), o el catedrático de la Facultad de Medicina vallisoletana ya mencionado, Fuente Arrimadas, que regaló su Patología quirúrgica. Más importantes fueron, sin duda, las donaciones hechas por los estudiosos locales ya citados: Alonso Cortés y Mantilla.

Las competencias del bibliotecario quedaron reguladas por los sucesivos reglamentos que especificaron, por ejemplo el de $1887^{33}$, que su ámbito de actuación venía constituido por la biblioteca y el gabinete de lectura y que en él estaba facultado para establecer el orden que creyera conveniente, con la aprobación de la directiva, preocupándose de que todos los periódicos se recogieran, tras su lectura por los socios, con el objeto de formar con ellos las correspondientes colecciones que, como se sabe, fueron una base importante en la constitución de la biblioteca. Era de su competencia asimismo, proponer a la Directiva qué suscripciones debían realizarse o suprimirse (por desgracia, no en todos los casos lo reflejan las actas) y las obras que debían de adquirirse, aunque a nuestro juicio una buena parte del fondo bibliográfico comprado no pasó por la sanción de la directiva. Por desgracia no conocemos casos en

30. Max Aub, La calle de Valverde, Diario El País, 2003, pp. 238-239.

31. ACRV, Libro de actas de la Junta directiva, 1906-1918, s. de 3-I-1907.

32. ACRV, Libro de actas de la Junta directiva, 1866-1888, s. de 26-V-1876.

33. En su artículo 33: Reglamento para el Círculo de Recreo de Valladolid, Valladolid, Imprenta y Librería nacional y extranjera de los Hijos de Rodríguez, 1887, p. 14. 
que los libros adquiridos lo fueron a instancias de los socios, lo que sería una información interesante. Debía también llevar un Indice de las obras existentes, "con especificación de autores, volúmenes de que constan, año de compra y forma de su encuadernación». Y, por último, debía pasarle al tesorero una cuenta justificada del importe de las obras adquiridas a lo largo del año, para incluirla en las cuentas generales, una información que tampoco ha llegado hasta nuestros días. Otros estatutos posteriores repitieron literalmente lo preceptuado en este de $1887^{34}$, aunque si nos vamos más adelante, al de 1930, vemos que se incluía entre las funciones del bibliotecario la de recomendar

que se evite todo acto que pueda interrumpir o molestar a los lectores o perturbar el silencio que en ellas [el gabinete de lectura y la biblioteca], siempre debe guardarse ${ }^{35}$.

\section{El FONDO BIbLIOGRÁfico DE ACUERDo CON EL INDICE DE I903}

La biblioteca del Círculo de Valladolid, sin ser especialmente cuantiosa, contaba en 1903 con un fondo digno, de 1.319 obras repartidas en 5.315 tomos $^{36}$. En años sucesivos, sabemos que continuó incrementándose, gracias a compras relativamente cuantiosas, como las realizadas a lo largo de 1907, consistentes en 300 obras nuevas, repartidas en 334 tomos, a lo que había que añadir que durante ese año el Círculo sostuvo la suscripción a 67 periódicos y revistas ${ }^{37}$. En 1918, por otro lado, se sabe que el fondo bibliográfico se incrementó en 216 volúmenes, y se da el interesante dato de que la biblioteca contaba ya entonces con 8.084 libros $^{38}$. No obstante, el análisis que aquí se está haciendo se atiene al fondo catalogado en 1903 que refleja fundamentalmente lo adquirido o ingresado en la segunda mitad del siglo XIX, quedándose al borde, pues, de la Edad de plata de la literatura española. Aún cuando, y según el testimonio de algún socio veterano, se sabe que este fondo fue sometido a

34. Así, el de 1904: Reglamento para el Círculo de Recreo de Valladolid, Valladolid, establecimiento tipográfico de F. Santarén Madrazo, 1904.

35. Círculo de Recreo de Valladolid, Reglamento, Artes gráficas Afrodisio Aguado, ValladolidPalencia, 1930, p. 22. También le encomendaba fijar en el sitio más a propósito, un cuadro con el reglamento que había de regir ambas dependencias, así como una relación de las obras que se fueran comprando, de los periódicos a los que el Círculo estaba suscrito y otros anuncios que estimara de interés.

36. La contabilización manual que hemos hecho de obras y tomos de las distintas secciones del Indice y que se reproduce más abajo en el propio texto, no es exactamente coincidente: 1.189 obras y 2.696 tomos, lo que puede ser debido a un error nuestro o del propio Mariscal; o al hecho de que, en un cierto número de casos, los tomos comprendieran en realidad varios volúmenes. Como elemento de comparación se puede aportar el dato de que la biblioteca del Casino de Zaragoza, en 1890 contenía 3.876 volúmenes, y la del Casino de Murcia, en 1915, 2.707: JeanClaude Vanhillé-Lité, Casinos y círculos de Zaragoza (1830-1908), Zaragoza, Diputación de Zaragoza, Institución «Fernando el Católico», 2001, p. 96.

37. ACRV, Libro de actas de las sesiones generales, 1854-1912, s. de 29-XII-1907.

38. ACRV, Libro de actas de las Juntas Generales, s. de 30-XII-1918. 
un expurgo durante la Guerra Civil, especialmente en lo relativo a obras de carácter pornográfico (de las que el catálogo no da ninguna pista, como es previsible), no existe constancia documental del mismo y, por tanto, de las pérdidas que pudo comportar ${ }^{39}$.

Una parte importante del mismo consistía en los tomos encuadernados de aquellas publicaciones periódicas que se conservaban, muy variadas y abundantes, y que se contabilizaban dentro del total de tomos antes consignado. En 1903, todos los fondos catalogados se repartían, como se ha comentado, en tres ubicaciones: a) la biblioteca propiamente dicha; b) el gabinete de lectura; y c) la sala de juntas. En las notas que el autor de este catálogo hacía figurar al margen respecto de algunos libros, destacan las pertenecientes a la Bibliothèque Scientifique Internationale, esto es, a la colección de divulgación científica ${ }^{40}$, del mismo título creada en 1873 por el editor Germer Baillière y por el científico Emile Alglave $^{41}$, a la que la entidad sin duda se había suscrito. Se trataba de una obra pensada para las bibliotecas, aunque era complementaria de otras revistas científicas de este mismo sello editorial ${ }^{42}$.

\section{No de obras y tomos de la Biblioteca del Círculo de Recreo en 1903}

\begin{tabular}{lrrr}
\multicolumn{1}{c}{ Tipo de obra } & a) obras & b) tomos & \multicolumn{1}{c}{ b/a } \\
Obras impresas & 1.229 & 2.598 & 2,1 \\
periódicos oficiales & 5 & 464 & 92,8 \\
períod. de ciencias o artes & 34 & 697 & 20,5 \\
periód. enciclópedicos y literarios & 46 & 1.527 & 33,19 \\
íd. satíricos y festivos & 5 & 29 & 5,8 \\
Total & $\mathbf{1 . 3 1 9}$ & $\mathbf{5 . 3 1 5}$ & $\mathbf{4 , 0 2}$
\end{tabular}

Indice de los libros de su biblioteca, p. 139

39. En el caso del Nuevo Casino de Pamplona, tal cosa sí que está documentada: se hizo un primer expurgo, en 1934, al parecer, por decisión interna, de las obras de carácter pornográfico que figuraran en el catálogo y luego otra $-\mathrm{u}$ otras-, ya durante la Guerra, que afectaron a 136 volúmenes: José del Guayo Lecuona y María Dolores Martínez Arce, El Nuevo Casino de Pamplona, 1856-2006, Pamplona, Nuevo Casino de Pamplona, 2006, pp. 158 y 163. El Casino de Vic también experimentó un expurgo en 1939: Santi Ponce y Maties Ramisa El Casino de Vic, 1848-2008, Vic, Eumo Editorial/Casino de Vic, 2008, p. 98.

40. O, mejor, de popularización y no vulgarización, ya que, en opinión de Alglave, era el pueblo, y no lo vulgar a quien habría que educar.

41. Cabe remitir a Valérie Tesnière, "Diffuser la science», en Le livre et l'historien. Études offertes en l'honneur du professeur Henri-Jean Martin, Genève, Librairie Droz, 1997.

42. Sobre la aparición de este nuevo género editorial consistente en la colección o «biblioteca»: Isabelle Olivero, Linvention de la collection. De la diffusion de la littérature et des savoirs à la formation du citoyen au XIX'e siécle, París, Éditions de l'IMEC/Éditions de la Maison des Sciences de l'Homme, 1999. Por lo que respecta a Espańa puede verse, pero ya para el siglo XX, y centrado en empresas innovadoras, como El cuento semanal: Alberto Sánchez Alvarez-Insúa, «Colecciones literarias», en J. A. Martínez Martín (dir.), Historia de la edición en España (1836-1936), Madrid, Marcial Pons, 2001, pp. 373-395. 
En el Indice se hacía primeramente un reparto por materias, excesivamente prolijo, que se recoge en la tabla siguiente, y se pasaba luego a una clasificación por autores, otra de publicaciones periódicas, distribuidas también entre diversos apartados, y una final de colecciones bibliográficas relevantes, donde, entre otras, constaba la Biblioteca de autores españoles, la Crónica de España por provincias, o las obras completas de autores como Chateaubriand ${ }^{43}$ o Voltaire ${ }^{44}$. Aunque existía un cierto volumen de obras en otros idiomas, por no decir que en francés, lo cierto es que eran muy minoritarias en el conjunto, a diferencia de lo que ocurrirá con las publicaciones periódicas en que hay más presencia de títulos en otras lenguas.

Un dato que Mariscal omite y que hubiera sido interesante contar con él es el del año de edición y el de su ingreso en la entidad lo que hubiera permitido dar una visión aproximada de las fluctuaciones anuales o los ritmos de compra de libros. Como se carece de los libros de contabilidad para estas etapas más antiguas de la vida de esta institución, tampoco se puede abordar por ahí, por los presupuestos anuales, el estudio de esta cuestión. Se verá, de todos modos, que por lo que hace a las publicaciones periódicas, ese aspecto sí que puede ser documentado gracias a este Indice.

\section{Campos temáticos comprendidos en la biblioteca del Círculo}

\begin{tabular}{lrrrr}
\multicolumn{1}{c}{ Disciplina } & No obras & $\%$ & No ts. & $\%$ \\
Administración & 11 & 1,18 & 42 & 1,55 \\
Agricultura & 17 & 1,42 & 30 & 1,11 \\
Arqueología & 7 & 0,58 & 21 & 0,77 \\
Astronomía & 15 & 1,26 & 20 & 0,74 \\
Bellas Artes & 38 & 3,19 & 65 & 2,41 \\
Bibliografías & 4 & 0,33 & 5 & 0,18 \\
Biografías & 36 & 3,02 & 57 & 2,11 \\
CC. Exactas & 3 & 0,25 & 3 & 0,11 \\
CC. Físico-químicas & 29 & 2,43 & 44 & 1,63 \\
CC. Naturales & 58 & 4,87 & 89 & 3,3 \\
CC. Sociales & 66 & 5,55 & 83 & 3,07 \\
Derecho & 80 & 6,72 & 333 & 12,35 \\
Economía Política & 7 & 0,58 & 7 & 0,26 \\
Enciclopedias & 13 & 1,09 & 230 & 8,53 \\
Exposiciones & 5 & 0,42 & 17 & 0,63 \\
Filosofía & 39 & 3,28 & 77 & 2,85 \\
Geograf., Geolog., Viajes & 47 & 3,95 & 135 & 5 \\
Historia & 125 & 10,5 & 403 & 14,94 \\
Idiomas & 14 & 1,17 & 24 & 0,89
\end{tabular}

43. Valencia, Cabrerizo, 1843-1850,17 tomos en 30 vols.

44. Euvres de Voltaire. Nouvelle édition avec des notes et des observations critiques... par M. Palissot, Paris, Servière-Stoupe, 1792-1802, 55 vols. 


Industria y Comercio
Literatura: Crítica, precept.
Literatura: Teatro
Literatura: Novelas
Literatura: Poesía
Medicina y Cirugía
Milicia
Política
Religión
Varios

Total

$\begin{array}{rrrr}15 & 1,26 & 21 & 0,77 \\ 88 & 7,4 & 162 & 7,05 \\ 8 & 0,67 & 12 & 0,44 \\ 217 & 18,25 & 299 & 11,09 \\ 71 & 5,97 & 87 & 3,22 \\ 19 & 1,59 & 128 & 4,74 \\ 71 & 5,97 & 93 & 3,44 \\ 25 & 2,1 & 47 & 1,74 \\ 56 & 4,7 & 157 & 5,82 \\ 5 & 0,42 & 5 & 0,18 \\ \mathbf{1 . 1 8 9} & \mathbf{1 0 0} & \mathbf{2 . 6 9 6} & \mathbf{1 0 0}\end{array}$

Las cifras ofrecidas, que discrepan en los totales de las aportadas por Mariscal, las hemos obtenido de la contabilización manual a partir de la relación de obras y tomos del Indice.

No puede olvidarse que esta biblioteca lo era de una institución de carácter recreativo, y en este sentido sería ilusorio esperar un catálogo muy poblado de sesudos autores o de obras de estudio. Si, por ejemplo, acude uno a la rúbrica «Filosofía», los mejor representados son dos eclesiásticos: Jaime Balmes y el padre Ceferino González, y la presencia de pensadores importantes en esta disciplina es escasa, limitándose a Platón, Aristóteles (en las traducciones que hizo Patricio de Azcárate para la Biblioteca Filosófica), o Inmanuel Kant. Está también el inevitable Herbert Spencer, tan expresivo de las corrientes de pensamiento dominantes en los últimos decenios del siglo XIX, pero es interesante subrayar la presencia de varios pensadores krausistas, como Francisco Giner, Manuel Sales y Ferré o el belga Gustave Tiberghien, así como de otros autores, sobre todo franceses, tales como Ernest Renan, Pierre-Joseph Proudhon, Théodule Ribot, Jules Payot o Alfred Fouillée, de bastante interés, no sólo en el campo estrictamente filosófico. Incluso bajo la rúbrica de "Ciencias sociales» figura una edición de El capital, de Karl Marx, muy probablemente la traducción inacabada que había hecho el médico y socialista argentino Juan Bautista Justo en la biblioteca de pensamiento socialista creada por García Quejido ${ }^{45}$.

Es conveniente subrayar cómo figuran en la biblioteca obras del filósofo escocés Alexander Bain ${ }^{46}$ y del anglo-norteamericano John William Draper, en particular su Historia de los conflictos entre la religión y la ciencia, en la que presentaba al catolicismo como el freno al progreso en la historia y que provocó una considerable polémica en una Europa muy sacudida por el Concilio Vaticano I y por el influjo del pensamiento evolucionista. Pues bien, en la biblioteca del Círculo está la traducción al español de esta obra, realizada por Augusto T. Arcimis y que lleva un sustancioso prólogo de Nicolás Salmerón,

45. Manuel Pérez Ledesma, El obrero consciente. Dirigentes, partidos y sindicatos en la II Internacional, Madrid, Alianza Editorial, 1987, pp. 155-156. Previamente habían aparecido otras dos traducciones, menos fidedignas, en La Emancipación y en el periódico federal La Vanguardia.

46. En concreto, La science et l'éducation, y L'esprit et le corps, pertenecientes a la BSI. 
que es uno de los textos claves para entender la postura ante la religión y ante el catolicismo por parte de los krausistas. Hay que hacer constar que en la biblioteca había también una traducción al francés de la misma obra, pues estaba incluida en la Bibliothèque Scientifique.

Pero en sustancia, como se ha dicho, hay poca filosofía y los autores mejor representados son dos sacerdotes beligerantes o críticos con el pensamiento moderno, sobre todo en el caso de Balmes. Si uno acude a la rúbrica «religión», aquí las obras son más abundantes y reflejan en cierto modo la importancia que la cuestión religiosa tuvo en el siglo XIX, probablemente bastante más desde el lado católico intransigente o ultramontano que desde el más tolerante o liberal: no se localiza, entre los autores extranjeros a ninguno de los más conocidos católicos liberales, como Dupanloup, Lamennais ${ }^{47}$ o el conde de Montalembert y sí, en cambio a algunos escritores situados en las posiciones contrarias, tales como los jesuitas Cretineau-Joly, Giovanni Perrone ${ }^{48}$ o Matteo Liberatore, que fue uno de los fundadores de la Civiltá Cattolica, así como diversos autores franceses claramente significados por su ultramontanismo y su combate contra el racionalismo, como el conde Joseph de Maistre (está su Du Pape, aunque traducido al castellano), el abbé Brispot, el canónigo Marius Aubert, el trapense y doctor en medicina Pierre-Jean-Corneille Debreyne, el también canónigo Duclot, entre otros.

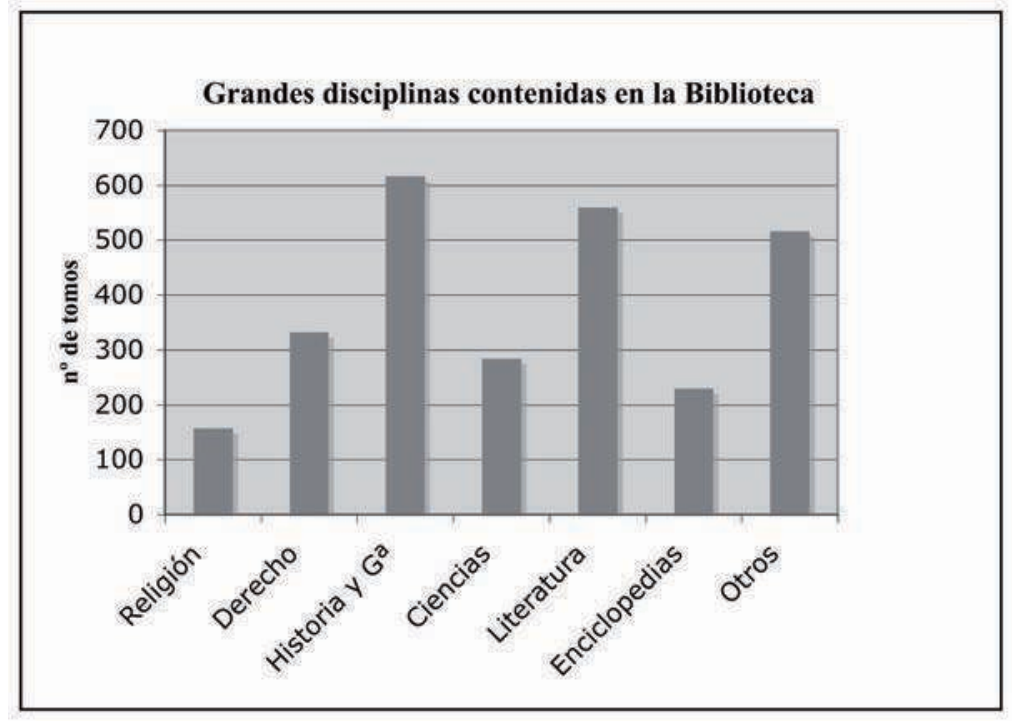

Por lo que hace a los autores españoles (o de lengua española), la tónica parece, en primer lugar, eclesiástica, pues buena parte de los autores son curas o frailes, además de integristas y, en algunos casos polemizadores respecto de

47. Aunque aparecen, no obstante, en otras rúbricas, con una obra aislada cada uno.

48. Perrone aparece citado en Ramón Pérez de Ayala, A.M.D.G., Madrid, Cátedra, 1983, p. 178, edic. de Andrés Amorós. 
textos que tuvieron gran repercusión en las querellas religiosas del siglo XIX, como ciertas obras de Draper y de Renan, presentes también en esta biblioteca. Habría que mencionar aquí a fray Tomás Cámara, a fray Ramón Buldú, al padre jesuíta Miguel Mir, al sacerdote chileno y estrecho colaborador de Pío IX, José Ignacio Víctor Eyzaguirre, junto con otros autores como Juan Juseu y Castanera, catedrático de teología y refutador de la vida de Jesús, de Renan ${ }^{49}$.

Es cierto, no obstante, que figuran obras de algunos prelados franceses defensores de las libertades galicanas, como H.-L.-C. Maret, obispo del Jura, o contrarios a la definición conciliar de la infalibilidad pontificia, como Monseñor Meignan, arzobispo de Tours, y que tomó parte en las sesiones del Concilio Vaticano I. Es de notar asimismo la presencia en esta sección de autores racionalistas como el economista belga Emile Laveleye ${ }^{50}$ y de otros intelectuales significados por sus posiciones heterodoxas, como Edgar Quinet (además del ya citado Renan $)^{51}$. Sin embargo, la tónica general de esta relativamente amplia sección es más bien integrista o, en todo caso, suspicaz respecto de las relaciones entre el dogma católico y la autoridad del Papa, por un lado, y la ciencia y el pensamiento modernos, si bien hay que matizar que esta orientación tropezó con serias resistencias dentro del Círculo, como evidencian las tensiones suscitadas con motivo de la elección de un bibliotecario durante el Sexenio democráticoen $1870,{ }^{52}$ en cuyo trasfondo estaba el descontento de un sector de los socios por la abundancia de obras de carácter religioso en la biblioteca. Por otro lado, no hay que olvidar que entidades recreativas como ésta conformaban espacios secularizados y en que la tolerancia respecto de las distintas opiniones políticas o religiosas era un supuesto clave para una convivencia civilizada de los socios. Y, finalmente, que este sesgo ultramontano que hemos advertido se contrapesaba, dentro de la propia biblioteca, con la marcada afición a autores como Emile Zola, con unas veinticinco obras aproximadamente en $1903^{53}$, o por la presencia de las obras completas de Voltaire.

Es curioso que el apartado «Economía política», sea tan pobre, agrupando tan sólo a siete autores, incluyendo aquí a un órgano estatal, la Junta de estadística y donde, si se descuenta a Pierre-Joseph Proudhon y al presbítero Marco Mastrofini, los escritores presentes son los españoles Adolfo Buylla, M. Miranda, José Sánchez Ocaña y el inevitable Juan Güell y Ferrer, bien conocido por sus posiciones proteccionistas que le llevaron a polemizar con

49. Hay referencias a este catedrático en la información elaborada sobre Luis Vidart en el Proyecto de filosofía en español: http://www.filosofia.org.

50. Y, en concreto, El porvenir religioso de los pueblos civilizados, Madrid, Imp. Manuel Ginés Hernández, 1876.

51. De Quinet: El cristianismo y la revolución francesa, Sevilla, Imp. Salvador Acuña y Cía, 1879, y El genio de las religiones, s.a., traducción de Ricardo Macías Picavea. De Renan: Dialogues et fragments philosophiques, y su Vida de Jesús, Barcelona, traducción de J. Adelantado, 1869.

52. ACRV, Libro de actas de la Junta directiva, 1866-1888, s. de 26-X-1870.

53. Véase Yvan Lissorgues, «El modelo teórico del Naturalismo. Ciencia positiva y literatura. Propuestas estéticas y temáticas. El debate sobre el naturalismo y el Simbolismo», en V. García de la Concha, Dir., Historia de la literatura española. Siglo XIX (II), coord., Leonardo Romero Tobar, Madrid, Espasa Calpe, 1998, pp. 19-31. 
miembros de la Escuela economista. Puede ser interesante subrayar la presencia de Mastrofini, matemático, teólogo y que se ocupó asimismo de cuestiones económicas, que publicó en 1831 un extenso estudio sobre la usura (traducido al castellano en 1859 con el título de Tratado de la usura), que es el que figura en esta biblioteca, en donde sostenía que no era delito buscar rentabilidad al dinero y que ni la Biblia ni la tradición eclesiástica prohibían obtener un interés justo por el dinero prestado lo que quizás conviene poner en relación con el gran peso de los comerciantes entre los socios de la entidad. Ciertamente, esta pobreza da que pensar, y no parece compaginarse muy bien con el fuerte peso, no sólo de comerciantes, sino también de especuladores o industriales en la creación del Círculo, en 1844 ¿Tendría razón Cossío en su descripción de la entidad, ya en una época posterior, en su novela Elvira Coloma, como una sociedad en la que los comerciantes no estaban bien vistos?

Puede ser también significativo el hecho de que la rúbrica "Milicia» esté más poblada que la de "Política», lo que cabría explicar en parte por la importancia del elemento militar entre los socios del Círculo (y más en una ciudad que era asiento de una Capitanía General y de la Academia de Caballería), así como porque la política en cuanto tal quedaba descartada reglamentariamente tanto de los fines como de las actividades de la sociedad. Sin embargo, hay que tener en cuenta que el casino en España fue una creación liberal y que la afluencia de políticos de ese signo a sus salones podía ser muy importante, y todo esto explicaría el que, dentro de este apartado destaquen más los autores de orientación liberal o, incluso, republicana, sobre los de signo contrario: a ese respecto figuran obras de moderados como Martínez de la Rosa y Bravo Murillo, junto con las de progresistas, tales como Joaquín María López y Salustiano de Olózaga, pero políticos republicanos como Pi y Margall y, más aún, Castelar, están bastante bien representados, lo que parece evidenciar que entre los socios existía un segmento que suscribía esa particular opción política.

Figuraban asimismo algunas obras de Lamennais ${ }^{54}$ y de John Stuart Mill ${ }^{55}$ y, en contraposición, los estudiosos o pensadores de signo antiliberal eran más escasos. Es cierto que esto se matizaba con la fuerte impronta católica integrista y ultramontana observada en el apartado "Religión», aunque esta aparente contradicción quizás no se lo parecía tanto a los liberales respetables que eran socios de la entidad. Otro dato significativo es que no se haya localizado a ningún escritor de filiación carlista y tan sólo dos obras que se refieren a esta temática, si bien sus autores, el aristócrata catalán Plácido de Montoliú y el clérigo y encendido polemista Miguel Sánchez López son clasificables más bien como monárquicos conservadores, antes que como carlistas ${ }^{56}$. Además la probable restricción en cuanto al ingreso de obras de carácter político viene

54. Felicité Robert de Lamennais, Obras politicas de Lamennais, Madrid, 1854.

55.John Stuart Mill, El gobierno representativo por... Vertido con notas y observaciones por D. Siro García del Mazo, s. 1., 1878.

56. Se puede consultar una amplia información sobre este presbítero en el Proyecto de filosofía en español: http://www.filosofia.org 
en parte compensada por la entrada, en el apartado de «Historia», de libros de memorias, o de estudios sobre la historia contemporánea que no dejaban de adentrarse, de una manera si se quiere más distanciada, en el análisis de hechos políticos más o menos recientes.

Ya se ha señalado antes que la biblioteca lo era de un centro recreativo, y esto explicaría la presencia, mucho más abundante, de literatura, historia, geografía y viajes, etc. Desde luego, la rúbrica «Historia», se encuentra bastante nutrida, sobre todo de autores espańoles que en un cierto número de casos habían compaginado su dedicación a esta disciplina, con la actividad política propiamente dicha. Tal circunstancia se daría, por ejemplo, en Javier de Burgos, Agustín Argüelles, Angel Fernández de los Ríos, Juan Valera, Eugenio García Ruiz, Evaristo San Miguel, el Conde de Toreno, el marqués de Pidal, Miguel Morayta, Antonio Alcalá Galiano, Fernando Fernández de Córdoba, Emilio Arjona, así como en los casos de Emilio Castelar, Francisco Pi y Margall o Víctor Balaguer, autores, en ocasiones, de obras que historiaban los sucesos contemporáneos en los que ellos mismos habían jugado un papel, incluso un importante papel. Ese estrecho maridaje se advierte asimismo en cuanto a la representación extranjera pudiendo citarse a autores como Adolphe Tiers, Alphonse de Lamartine, Louis Blanc, Victor Duruy o el propio Napoleón III, en cuya fase del Imperio liberal fue ministro el último historiador citado (Duruy).

De todas las maneras, el perfil de buena parte de los autores que figuran en este apartado es el de estudiosos o compiladores de los sucesos históricos, en su calidad de profesores universitarios, de académicos de la Historia, o, más en general, de escritores públicos. Por lo que respecta a autores españoles, cabría citar aquí, entre otros, a Juan Ortega Rubio, que fue catedrático de la Universidad de Valladolid y socio del Círculo, a Pedro Antonio de Alarcón, Cesáreo Fernández Duro, Matías Sangrador, Modesto Lafuente, José Amador de los Ríos, Manuel Sales y Ferré, Antonio Pirala, Antonio Ferrer del Río, Andrés Borrego, Manuel Villar y Macías, Ildefonso Antonio Bermejo, José Godoy Alcántara, José Coroleu, entre otros. Debe destacarse también la existencia de grandes obras de conjunto, abarcadoras de la historia universal, como las del alemán Gregor Weber, que tradujo al español Julián Sanz del Río ${ }^{57}$, el italiano Cesare Cantú, inevitable en las bibliotecas españolas de la segunda mitad del siglo XIX, o el reputado historiador del derecho de la Universidad de Gante, perteneciente a la corriente krausista, François Laurent, cuya obra Etudes sur l'histoire de l'humanité, en 18 volúmenes, figura en esta biblioteca ${ }^{58}$. Otra gran compilación, presente asimismo, era la realizada por el alemán Wilhelm Oncken.

Figuran asimismo en esta sección algunos historiadores extranjeros que se

57. Gregorio Weber, Compendio de la historia universal, escrito en alemán por el Dr...., catedrático de la Universidad de Heidelberg, traducido de la quinta edición en correspondencia con el autor, y aumentado con varias consideraciones generales y notas por D. Julián Sanz del Río, 4 vols., Madrid, Imprenta de Díaz y Cía, 1853-1856.

58. François Laurent, Études sur l'histoire de l'humanité, Bruxelles, Méline, Cans et Cie., 1861-1870. 
interesaron por la historia de España, como el autor escocés, muy influyente entre los ilustrados españoles, William Robertson, que escribió sobre el emperador Carlos V y la América española ${ }^{59}$; como el norteamericano William Prescott, un hispanista avant la lettre, cuyos trabajos históricos sobre los Reyes Católicos o sobre la conquista de Méjico fueron muy apreciados en su tiempo, también en Espańa, donde contó con la colaboración del erudito y académico Pascual de Gayangos; o el historiador holandés (pero que provenía de una familia de hugonotes franceses), Reinhart Dozy, una referencia fundamental en el estudio de la dominación musulmana en España. Habría que agregar a esta relación al prestigioso filólogo británico, Henry Bradley, estudioso de la época visigoda en España.

Otra nota de interés, que permite advertir la atracción que, hasta en una entidad recreativa como ésta, podían ejercer nuevas especialidades históricas como la arqueología o la prehistoria es la existencia entre los fondos de la biblioteca, de autores como el paleontólogo marqués de Nadaillac, el arqueólogo y etnólogo Gabriel de Mortillet, cuya orientación ideológica, de signo evolucionista, debía de ser bastante distinta del anterior. Pero cabe mencionar asimismo a otro arqueólogo galo, muy relacionado con Mortillet, Emile Cartailhac, así como al divulgador de los avances en la prehistoria, teniendo muy en cuenta las tesis de Darwin o Lyell, Sir John Lubbock. Y ya sin esa orientación tan especializada, la nómina de autores extranjeros debería ampliarse para incluir a clásicos como Tucídides, Ibn-Adhari, Theodore Mommsen o Edward Gibbon.

\section{LAS REVISTAS}

No se extenderá aquí la búsqueda a otras rúbricas, como la literatura en sus diferentes secciones, ya que esto exigiría de un acopio de información bibliográfica en muy diferentes ramos del saber o de la cultura que quizás no se justifique demasiado en el caso de una biblioteca que no era en modo alguno excepcional, como ésta del Círculo vallisoletano. Puede ser de más interés dirigir la atención hacia la sección de publicaciones periódicas, ya que aquí la información que aporta el Indice entra en algunos pormenores como si se mantuvieran vivas dichas publicaciones o, en caso contrario, el tiempo que duró la suscripción, el número de tomos conservados, y las clasifica en varios grandes apartados: a) periódicos oficiales; b) publicaciones periódicas de materia determinada en ciencias o artes; c) enciclopédicas y literarias; y d) satíricopolíticas, festivas y jocosas. El autor del Indice no incluye en esta relación la prensa diaria (salvo la oficial), que llegaba en abundancia al gabinete de lectura y que constituía un importante motivo de atracción para los socios ${ }^{60}$. De todos

59. En torno a esa influencia puede verse: José María Portillo Valdés, Revolución de nación. Orígenes de la cultura constitucional en España, 1780-1812, Madrid, Centro de estudios políticos y constitucionales, 2000, p. 65 y ss.

60. Es lástima que entre la documentación conservada, no figuren facturas y, entre ellas, las de los abonos sucesivos a todas estas publicaciones, como sí sucede, en cambio en otros casinos, 
modos, y teniendo en cuenta el papel mucho más decisivo y específico de las revistas en la difusión de la cultura, del pensamiento, de los conocimientos científicos, respecto del periódico, creemos aquí que es mucho más interesante centrarse prioritariamente en su estudio ${ }^{61}$.

\section{Publicaciones periódicas vivas en 1904}

\section{Titulo}

Boletin Oficial de la Provincia de Valladolid

Diario Oficial del Ministerio de la Guerra

Gaceta de Madrid

Boletín de la Revista de Legislación y Jurisprudencia

Revue Scientifique de la France et de l'étranger

Memorial de Artillería

Revista Cientifico Militar

Revista de Obras Públicas

Revista general de legislación y jurisprudencia

Revista de Montes

Revue d'Economie politique

Revue de Médecine

Revue de Chirurgie

L'Illustration

La Nature

La España moderna

La Ilustración artistica

La Ilustración española y americana

L'Illustrazione italiana

Revista contemporánea

Revue des deux Mondes

$\begin{array}{cc}\text { Carácter } & \text { fecha inicio } \\ \text { Of. } & 1871 \\ & 1896 \\ & 1857 \\ \text { Cc./A. } & 1870 \\ & 1873 \\ & 1897 \\ & 1876 \\ & 1896 \\ & 1870 \\ & 1877 \\ & 1895 \\ & 1890 \\ & 1890 \\ \text { Enc./lit. } & 1854 \\ & 1877 \\ & 1889 \\ & 1884 \\ & 1870 \\ & 1875 \\ & 1875 \\ & 1844\end{array}$

De la relación anterior, y a falta de hacer, cuando se finalice este análisis, una consideración más detenida, pueden destacarse varias notas, como el carácter, se podría decir que "paraoficial» que tenía una entidad como ésta, como prueba la recepción de la Gaceta de Madrid y del Boletín oficial de la provincia de Valladolid, o el peso del elemento militar, así como de los profesionales del derecho y la medicina. También, de los ingenieros, que estaban muy bien representados dentro del Círculo; la afición de los socios a las publicaciones

como el de Llagostera, en Gerona: Pere Solá i Gussinyer, «El Casino Llagosterenc, de la primera dictadura a la guerra civil», en Revista de Girona, 128 (maig-juny 1988), pp. 22-23.

61. Georges Sorel le decía a Edouard Berth lo siguiente, en 1907: "Les journaux font du journalisme; les revues font de la culture; il ne faut pas se laisser aller à confondre les rôles». La cita en Michel Leymarie, «Introduction. La belle époque des revues?», en J. Pluet-Despatin, M. Leymarie y J.-Y. Mollier, Dirs., La belle époque des revues, 1880-1914, Paris, Éditions de L'IMEC, 2002, p. 11. 
ilustradas y, en fin, el tributo que se rendía al pensamiento moderno, a través de varias revistas muy prestigiosas en ese campo (La España moderna; Revista contemporánea y la Revue des deux mondes).

Pero las publicaciones periódicas recibidas en la entidad, cabe también distribuirlas por periodos quinquenales, a contar desde la fecha de apertura de la misma (1844), consignando el dato del año en que se hizo la suscripción y el número de tomos que se guardaban. En el Indice se informaba también el local del Círculo en donde estaba depositada la publicación, lo que no deja de tener cierto interés, como se advertirá. En el caso de aquellas que se mantenían vivas o cuya suscripción duró 5 o más años, esa información se hace figurar también en la tabla siguiente:

\section{Suscripción a revistas por quinquenios (1844-1903)}

\section{Titulo}

Annuaire de deux mondes, Histoire génerale des divers états

El pensamiento de la Nación

El Museo de las familias

Revista de Madrid

Revista de España y de Indias

Revue Britannique

Revue des deux mondes

Semanario pintoresco español

Fray Gerundio

L'Illustration

La Sociedad

La Ilustración

Gaceta de Madrid

Journal des économistes

L'Année scientifique et industrielle

Le Tour du monde (Journal des voyages)

La América

Revue germanique

The Illustrated London News

Gaceta industrial

El Museo universal

Illustrierte Zeitung

Revista Ibérica

Revue moderne año suscrip.

5 o + ańos

No ts.

[1844-50]

1850

1850-63

10

1846

1846

1844

1845

1844

1844

?

?

[1851-55]

1854

1851

1853

[1856-60]

1857

1857

1857

1860

1857

1858

1857

[1861-65]

viva

viva 
[1866-70]

Diario de sesiones de las Cortes

1869

1869-96

Boletín de la revista de legislación y

1870

viva

jurisprudencia

1866

Revista general de legislación y

1870

viva

84

jurisprudencia

Cosmos. Revue encyclopédique

1866

1866-70

9

1870

La Ilustración de Madrid

1870

viva

1868

1868-94

142

1869

2

La Flaca

1869

1869-72

[1871-75]

Boletín oficial de la provincia de Valladolid

1871

viva

Boletin oficial de ventas de Bienes

1873

1873-88

24

1872

El pabellón médico

1873

1873-96

Gaceta de los caminos de hierro

1873

viva

Revue scientifique de la France et de

l'étranger

Revista de los tribunales

1875

1875-902

59

La defensa de la sociedad

1872

l'Illustrazione italiana

1875

1872-79

6

La revue politique et littéraire

1873

Revista contemporánea

1875

viva

14

Revista europea

1874

1873-81

[1876-80]

Boletín de la revista de los tribunales

1878

1878-82

El siglo médico

1878-901

El anfiteatro anatómico español

1878

Gaceta agricola

1876

1876

1876-94

63

Revista cientifico militar

1876

Revista de montes

1877

Día de moda

1880

El mundo ilustrado

1879

viva

35

viva

23

El campo (Agricultura, jardinería,

1876

1879-84

1

6

sport)

$1876-92 \quad 16$

La Academia

1879

La Civilización

1878

La Nature

1877

La naturaleza

La civilización católica

1878

El loro

1879

1880

1878-91

viva

La Ilustración militar 


\begin{tabular}{|c|c|c|c|}
\hline Petit Journal pour rire & $\begin{array}{c}1880 \\
{[\mathbf{1 8 8 1 - 8 5}]}\end{array}$ & 1880-89 & 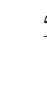 \\
\hline La semana industrial & 1882 & $1882-87$ & 6 \\
\hline La ciudad de Dios & 1884 & $1884-901$ & 48 \\
\hline La ilustración nacional & 1885 & $1885-900$ & 14 \\
\hline La Ilustración artística & 1884 & viva & 17 \\
\hline & {$[1885-90]$} & & \\
\hline Anales de historia natural & 1888 & $1888-95$ & 7 \\
\hline $\begin{array}{l}\text { Comptes rendus des séances de } \\
\text { l'Académie dessciences }\end{array}$ & 1888 & 1888-92 & 10 \\
\hline Revue de Médecine & 1890 & viva & 13 \\
\hline Revue de Chirurgie & 1890 & viva & 14 \\
\hline La España moderna & 1889 & viva & 62 \\
\hline 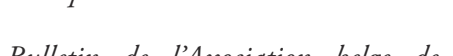 & {$[1891-95]$} & & \\
\hline $\begin{array}{l}\text { Bulletin de lAssociation belge de } \\
\text { photographie }\end{array}$ & 1895 & & 1 \\
\hline Crónica del sport & 1893 & & 2 \\
\hline L'art pour tous, industriel et décoratif & 1894 & & 3 \\
\hline Revista de derecho y sociología & 1895 & & 1 \\
\hline Revista política & 1893 & & 1 \\
\hline $\begin{array}{l}\text { Revue philosophique de la France et } \\
\text { de l'étranger }\end{array}$ & 1894 & $1894-901$ & 16 \\
\hline Revue d'économie politique & 1895 & viva & 7 \\
\hline Blanco y Negro & 1895 & 1895-99 & 3 \\
\hline Pro Patria & 1894 & & 1 \\
\hline Revista internacional & 1894 & & 6 \\
\hline The Magazine of art & 1894 & $1894-95$ & 2 \\
\hline & {$[1896-900]$} & & \\
\hline $\begin{array}{l}\text { Boletin oficial del Ministerio de la } \\
\text { Guerra }\end{array}$ & 1896 & viva & 28 \\
\hline $\begin{array}{l}\text { Bulletin de l'Association des ingénieurs } \\
\text { électriciens }\end{array}$ & 1897 & & 1 \\
\hline El mundo naval ilustrado & 1897 & & 2 \\
\hline Memorial de Artilleria & 1897 & viva & 7 \\
\hline Revista de obras públicas & 1896 & viva & 8 \\
\hline & {$[1901-\ldots]$} & & \\
\hline Nuestro tiempo & 1901 & & 1 \\
\hline
\end{tabular}

En total, y sin contabilizar la prensa política o de información general, la entidad habría estado suscrita, en el periodo 1844-1903, a 88 publicaciones, algunas de ellas de carácter diario, como la Gaceta de Madrid, el Boletín Oficial de la provincia, el Diario oficial del Ministerio de la Guerra, aunque lo que predominan son aquellas a las que la Sociedad estuvo suscrita por muy poco tiempo o que tenían una menor frecuencia en su periodicidad ${ }^{62}$. En todo

62. En el caso de la biblioteca del Casino de Zaragoza se sabe que hacia los años 80 del siglo XX, contaba, entre periódicos y revistas, con 194 publicaciones periódicas, aunque es de suponer 
caso, lo que se registra son las publicaciones que la entidad decidió conservar, mandándolas encuadernar, lo que sugiere que quizás hubo otras publicaciones -aparte de la prensa diaria-, a las que el Círculo estuvo suscrito, pero que no se guardaron o que, aún encuadernadas, se perdieron o por alguna razón se decidió prescindir de ellas.

Un elemento de juicio interesante puede ser el de saber cuántas de estas publicaciones eran españolas y qué otras, extranjeras. Pues bien, en total, había 27 publicaciones extranjeras, el 30,6 \%, pero con la particularidad que de ellas 24 eran de lengua francesa, habiendo solamente dos revistas inglesas, otra italiana y otra alemana, las últimas de carácter ilustrado. Resulta evidente que la difusión de las novedades en el pensamiento, la literatura, la economía, las ciencias, entre los grupos más acomodados, entre la burguesía de la época (de aquellos que sabían francés, convendría matizar), se llevaba a cabo principalmente a través de la lengua francesa. Es verdad que este tipo de revistas hay que pensar que resultarían también solicitadas por la minoría de socios de esa nacionalidad que llegó a revestir alguna importancia sobre todo por la centralidad de Valladolid en la red ferroviaria de la Compañía del Norte. Es revelador que durante la Restauración, existiera un viceconsulado de Francia en la ciudad, o que se hiciera un homenaje a ese país en 1879 por sus socorros a las provincias de Levante, que sufrieron una grave inundación en el mes de octubre, organizando un concierto al que se invitó al vicecónsul y a las autoridades locales ${ }^{63}$

Dentro de ese conjunto de revistas extranjeras, una parte no desdeñable estaba formada por revistas ilustradas, muy del gusto de los socios de este tipo de entidades (L'Illustration, The Illustrated London News, L'Illustrazione italiana o Illustrirte Zeitung, a las que seguramente habría que añadir otras de distinto carácter, como Le tour du monde. Revue des voyages et des voyageurs ${ }^{64}$, pero pródigamente ilustradas). Otras, como la Revue Germanique y la Revue Britannique permitían sin duda, a través de la imprescindible lengua francesa, estar al corriente de las principales novedades en esos dos ámbitos lingüísticos y se ha señalado, por ello, que desempeñaron el papel de propagadores o intermediarios culturales ${ }^{65}$. Pero si se prescinde de las ilustradas o de otras de carácter humorístico o satírico como Le Charivari o Le petit journal pour rire,

que se incluirían en esta cifra revistas de otras épocas, ya extinguidas: María Remedios Moralejo Âlvarez y María Dolores Pedraza Prades, La biblioteca del Casino de Zaragoza, op. cit., p. 9. En otro estudio se recogen los títulos de las revistas antiguas, según venían anotadas en el catálogo de 1916: Jean-Claude Vanhillé-Lité, Casinos y círculos de Zaragoza (1830-1908), op. cit., p. 96.

63. ACRV, Libro de actas de la Junta directiva, 1866-1888, s. de 6-XII-1879.

64. Creada por Hachette, quien confió su dirección al sansimoniano Edouard Charton: Jean-Yves Mollier, Louis Hachette (1800-1864). Le fondateur d'un empire, París, Fayard, 1999, p. $369-370$ y 429 .

65. Thomas Loué, «Les passeurs culturels au risque des revues (France, $\mathrm{XIX}^{\mathrm{e}}$ et $\mathrm{XX}^{\mathrm{e}}$ siècles)», en D. Cooper-Richet, J.-Y. Mollier y A. Silem, Dirs., Passeurs culturels dans le monde des médias et de l'édition en Europe (XIX'e et XXe siècles), París, Presses de l'Enssib, 2005, p. 199. No estamos seguros de si el término «intermediario cultural» es la traducción más correcta de passeur culturel. 
lo que predomina es más bien un tipo de revista de literatura y pensamiento, o de difusión de las novedades científicas, filosóficas, algunas dirigidas a un sector profesional determinado, como los médicos.

Es en esta modalidad donde cabe hallar las revistas de mayor interés como la Revue scientifique de la France et de l'étranger, la Revue philosophique de la France et de l'étranger, La Revue politique et littéraire, editadas las tres por Germer Baillière, la misma librería parisina que editaba la Bibliothèque Scientifique Internationale, y que debía de contar con una eficaz red de distribución en Europa y España (a través de la red familiar de distribución internacional puesta en pie por su tío Jean-Baptiste ${ }^{66}$ ), pero se complementan con otras, como L'Année scientifique et industrielle ${ }^{67}$, las Comptes rendus de l'Académie des Sciences, Cosmos. Revue encyclopédique, dirigida en este caso por el jesuita y matemático François-Marie-Napoléon Moigno, todas ellas con un marcado propósito de vulgarización y que contribuyeron a crear lo que Anne Rasmussen ha calificado como una «internationale scientifique» ${ }^{68}$. $\mathrm{O}$, en fin, La Nature, fundada en 1873 por Gaston Tissandier ${ }^{69}$. Y por supuesto, la Sociedad continuaba suscrita a una publicación que era en sí misma una institución cultural, la Revue des Deux Mondes ${ }^{70}$, dirigida a las elites económica y socialmente dominantes en una época en que, como se ha dicho, se mantenía una adecuación entre espacio público y elites cultivadas muy en la línea de lo señalado por J. Habermas ${ }^{71}$. Y que marcaría el modelo para otras revistas políticas y literarias, orientadas, hasta la Belle époque, a un "public d'élite», tal y como se manifestaba en la Revue de Paris en $1896^{72}$. Se recibió también, entre 1850 y 1863, el Annuaire des Deux Mondes. Histoire générale des divers états, que publicaba dicha revista.

En cualquier modo, este bloque de publicaciones foráneas parece significar que existió al menos una minoría de socios interesado en seguir las evoluciones

66. Valérie Tesnière, Le Quadrige. Un siècle d'édition universitaire 1860-1968, Paris, PUF, 2001, p. 50. Sobre la rama española de los Baillière hay amplia información en: Jean-François Botrel, Libros, prensa y lectura en la España del siglo XIX, Madrid, Fundación Germán Sánchez Ruipérez, 1993, p. 543 y ss.

67. Este anuario fue lanzado también, en 1856, por el editor Louis Hachette, quien encomendó su dirección y la recopilación de los artículos que lo componían al científico Louis Figuier: Jean-Yves Mollier, Louis Hachette (1800-1864), op. cit., p. 369.

68. Véase Thomas Loué, «Les passeurs culturels...», art. cit., p. 200.

69. Valérie Tesnière, Le Quadrige, op. cit., p. 39. Es verdad que esa creación la llevaron a cabo sobre todo las revistas propiamente científicas y no de alta vulgarización, que florecieron en la Belle Epoque, gracias en buena medida a unas cuantas casas editoriales francesas, como Gauthier-Villars o Masson: Vincent Duclert y Anne Rasmussen, «Les revues scientifiques et la dynamique de la recherche», en J. Pluet-Despatin, M. Leymarie y J.-Y. Mollier, Dirs., La belle époque des revues, 1880-1914, op. cit., pp. 237-254.

70. Véase, entre otros estudios que se le han dedicado: Gabriel de Broglie, Histoire politique de la 'Revue des deux mondes', de 1829 à 1979, Paris, Librairie Académique Perrin, 1979, pról. de Maurice Schumann.

71. Thomas Loué, «Les passeurs culturels...», art. cit., pp. 197-198.

72. Thomas Loué, «Un modèle matriciel: les revues de culture générale», en J. Pluet-Despatin, M. Leymarie y J.-Y. Mollier, Dirs., La belle époque des revues, 1880-1914, op. cit. p. 62. 
del pensamiento y de la ciencia modernos, en una etapa en que justamente esos avances hacían que se agrandara el foso entre la ciencia y la religión, entre el dogma católico y el pensamiento libre y que provocaron importantes debates o declaraciones de principios para los que las revistas fueron el vehículo más idóneo ${ }^{73}$. Aporta también un toque cosmopolita al fondo bibliográfico analizado, que equilibra o compensa la orientación preferentemente nacional o en lengua castellana de los libros anteriormente estudiados. Eso se ha verificado también para otros casinos ${ }^{74}$.

No deja de ser algo intrigante que un tipo de entidades dedicadas al recreo, pudieran servir de puente con esas polémicas realidades a través del amplio muestrario de publicaciones periódicas que recibían. Esto se complementaba, además con determinadas revistas españolas que llegaban también al gabinete de lectura. De todos modos, a la hora de evaluar de un modo más ajustado el verdadero interés que un sector de los socios pudiera sentir hacia esos terrenos, se hace preciso tener muy en cuenta la continuidad o el carácter efímero de las suscripciones a partir por ejemplo, del dato del número de tomos que se conservaban.

En cuanto a las publicaciones periódicas españolas, fundamentalmente revistas, un primer conjunto estaría formado por las de carácter oficial, y aquí cabe incluir no sólo las ya apuntadas (Gaceta de Madrid, etc.), sino también, el Diario de sesiones de las Cortes, el Boletín de ventas de Bienes Nacionales, la Gaceta agricola del Ministerio de Fomento, el Memorial de Artillería (publicada por la Academia de dicha arma), además de otras a las que cabría considerar como los órganos de expresión de determinados grupos profesionales estrechamente vinculados al Estado como los ingenieros industriales, de montes y de caminos: la Gaceta industrial, fundada por el ingeniero industrial José Alcover, o la Revista de Montes y la Revista de Obras Públicas ${ }^{75}$. Otro conjunto estaría formado por publicaciones de carácter jurídico, lo cual hallaba su razón de ser en una ciudad con una fuerte tradición en ese campo, y que era el asiento de una Audiencia territorial. Aquí estará en primer término la Revista general de legislación y jurisprudencia, creada en 1853 por José Reus García, además del Boletín de la Revista de Legislación y Jurisprudencia, del Colegio de abogados de Madrid, La Justicia, revista de legislación, la Revista de los tribunales y la administración, creada en 1850 por M. Martínez Alcubilla, y el Boletín de la revista de los tribunales, o, en fin, la Revista de derecho y sociología, fundada en 1895 por el krausoinstitucionista Adolfo Posada, pero de la que sólo se publicó un número.

73. Michel Leymarie, «Introduction. La belle époque des revues?», op. cit., p. 16.

74. Así, el de Tenerife aunque, en este caso, el lado cosmopolita es más acentuado del mismo modo que el toque británico: Agustín Guimerá Ravinas y Alberto Darías Príncipe, El Casino de Tenerife (1840-1990), Santa Cruz de Tenerife, 1992, p. 95.

75. Véase, Darina Martykánova, «Por Los caminos del progreso. El universo ideológico de los ingenieros de caminos españoles a través de la Revista de Obras Públicas (1853-1899)", en Ayer, 68 (2007-4), pp. 193-219. 
El Círculo estuvo suscrito asimismo a varias revistas de interés para los profesionales de la medicina, uno de los estudios de más tradición en la Universidad vallisoletana. Además de la Revue de Médecine o de la Revue de Chirurgie se recibieron, en el último tercio del siglo, títulos como El pabellón médico, órgano de la Academia médico quirúrgica matritense (se subtitulaba: revista científica y profesional de medicina, cirugía y farmacia), El siglo médico, creada en 1854 por el higienista Francisco Méndez Álvaro, o El anfiteatro anatómico español, fundada en 1873 por el doctor Pedro González de Velasco, creador del Museo Antropológico y en la que colaboraron científicos de la talla de Luis Simarro.

Ya se ha subrayado cómo el hecho de que la Sociedad estuviera suscrita a varias publicaciones de carácter castrense se justificaba en parte por la importante presencia del colectivo militar entre los socios. Es cierto, no obstante, que la materialización de algunas de esas suscripciones (así, del Diario oficial del Ministerio de la Guerra y del Memorial de Artillería), pudo estar muy influida por la coyuntura belicista de los últimos años del siglo XIX en que España perdió sus últimas colonias ultramarinas y hubo un resurgir del patriotismo que se dejó notar también en este tipo de entidades. Justamente por entonces es cuando se estaba perfilando la profesión militar como una especie de casta separada de los paisanos y con una visión exclusivista de la patria.

Sorprende que, siendo considerada Valladolid como el centro de los intereses trigueros a escala española, haya muy pocas publicaciones de carácter agrícola, tan solo dos: la Gaceta agrícola del Ministerio de Fomento, ya comentada, y que era una publicación oficial, y otra titulada El campo (agricultura, jardinería, sport) que, por su subtítulo parece evidenciar que la atención a las cuestiones agrícolas no era en modo alguno exclusiva. Es cierto que el principal periódico local, El Norte de Castilla, que sin duda se recibía, estaba considerado como una de las voces más autorizadas en esta temática vista desde una óptica proteccionista. En cuanto a las de carácter económico, tampoco parece que la economía fuera considerada como una disciplina que pudiera interesar de un modo prioritario a los socios: puede resultar expresivo a estos efectos, el que a finales de 1858 uno de los directivos, Tomás Alfaro, manifestara su extrañeza por el hecho de que en una sociedad en la que buena parte de sus miembros eran comerciantes, no se recibiesen diarios puramente mercantiles, por lo que se tomó el acuerdo de suscribir al Círculo a tres diarios de esa índole, aunque por desgracia no se relacionan sus títulos

Es cierto que la Sociedad estuvo suscrita a algunas publicaciones francesas muy relevantes en ese plano, como el Journal des économistes, aparecida en 1841 y editada por Guillaumin, que se convirtió en uno de los principales órganos de expresión de la economía política liberal, aún cuando muy probablemente la suscripción duró poco tiempo. También, a la Revue d'économie politique, aparecida en 1887 en parte como reacción a la ortodoxia liberal de la anterior, una suscripción que se mantenía viva en $1904^{76}$. Es verdad que del lado

76. Sobre ambas revistas: Lucette Le Van-Lemesle, «Les revues d'économie», en J. Pluet- 
español, la Sociedad recibió una publicación como la Gaceta de los caminos de hierro, fundada en 1856 por Félix de Bona, miembro de la escuela economista, que, además de concentrarse en toda la temática ferroviaria, prestaba mucha atención a la economía en su conjunto. La semana industrial, cabría también ser encuadrada en este campo.

Pero, de todos modos, y enlazando con lo dicho sobre las publicaciones de carácter agrícola, sería seguramente un error enfocar a este Círculo como un centro en el que estaban en primer plano los intereses económicos y corporativos de sus socios, pese a que fuera frecuentado por individuos que por sus posesiones territoriales, su directa implicación en la industria, el comercio o las finanzas locales, podría pensarse que estarían tentados de utilizar a la Sociedad como plataforma de sus intereses. En una etapa como esta de la Restauración, en la que en Valladolid existía ya una pluralidad y especialidad asociativas importantes, esas funciones las desempeńaban seguramente otras entidades, con una explícita vocación de intervenir en esos planos de la economía y de los intereses corporativos.

A ese respecto, lo que quizás se acomodaba mejor a lo que en realidad era el Círculo, a la principal de sus funciones, venía constituido por el conjunto formado por las publicaciones ilustradas y las humorísticas o satíricas ${ }^{77}$ : dejando aparte revistas que contenían un material gráfico importante (El Museo de las familias, el Semanario pintoresco, el Museo universal), aquellas en cuyo título aparecía el sustantivo «ilustración», o el adjetivo «ilustrado» eran siete a las que, si se suman las extranjeras ya citadas y la revista Blanco y Negro, cuyo principal atractivo residía en su componente gráfico, sale un total de $\operatorname{doce}^{78}$. Que seguramente serían más si se conociera mejor todo este repertorio de publicaciones recibidas en la entidad. Aquí se relaciona el total (incluyendo también las revistas extranjeras):

Despatin, M. Leymarie y J.-Y. Mollier, Dirs., La belle époque des revues, 1880-1914, op. cit., pp. 255-268.

77. En 1858 se había tomado el acuerdo de suscribirse a un "periódico de caricaturas», que proporcionara entretenimiento «a los que obran por estas impresiones»: ACRV, Libro de actas de la junta directiva, 1854-1866, s. de 26-X-1858.

78. Para Maurice Agulhon, el siglo XIX fue el siglo de la imagen, frente a ideas preconcebidas o tópicos que atribuyen reductivamente esa especificidad al XX. Llama la atención sobre cómo, en dicha centuria, lo impreso, concebido como soporte del mensaje discursivo y, por tanto, antagonista posible del mensaje visual, se convierte también, para lo visual mismo, como un soporte más, y con una mayor irradiación: Maurice Agulhon, "Préface» a S. Michaud, J.-Y. Mollier y N. Savy, Usages de l'image au XIX' siècle, Paris, Éditions Créaphis, 1992, s. p. Cabe citar, en esta misma obra, por la importancia que concede a las publicaciones ilustradas de cara a difundir imágenes de los museos: Chantal Georgel, «Le Musée en représentation», pp. 143151. Se puede ver, en fin, por su evidente conexión con el tema: Philippe Kaenel, Le métier d'illustrateur 1830-1880. Rodolphe Töpffer, J.-J. Grandville, Gustave Doré, Genève, Librairie Droz, 2005, 2a ed. 


\section{Publicaciones ilustradas}

$\begin{array}{lc}\text { Título } & \begin{array}{c}\text { Año } \\ \text { suscripción }\end{array} \\ \text { L'llustration } & 1854 \\ \text { La Ilustración } & 1853 \\ \text { The Illustrated London News } & 1857 \\ \text { Illustrirte Zeitung } & 1865 \\ \text { La Ilustración de Madrid } & 1870 \\ \text { La Ilustración Española y Americana } & 1870 \\ \text { L'Illustrazione Italiana } & 1875 \\ \text { El mundo ilustrado } & 1879 \\ \text { La Ilustración nacional } & 1885 \\ \text { La Ilustración artística } & 1884 \\ \text { Blanco y Negro } & 1895 \\ \text { El mundo naval ilustrado } & 1897\end{array}$

Habría que mencionar, en fin, una serie de revistas españolas de pensamiento que evidencian de nuevo que existía un segmento de los socios con inquietudes intelectuales y para los que el surtido de publicaciones del Círculo desempeñaba una función importante, facilitándoles la puesta al día en una serie de campos, el seguimiento de las principales polémicas en materia científica, literaria o filosófica o, en fin, el conocimiento de relevantes autores extranjeros desconocidos de otro modo para el público español. Aquí cabría reseñar La Revista ibérica, de signo krausista, y cuyo principal impulsor fue Francisco de Paula Canalejas, la Revista de España, creada por José Luis Albareda, Revista contemporánea, de José del Perojo, la Revista europea, de Medina y Navarro Editores o, en fin, La España moderna, creada por un relevante intermediario cultural, José Lázaro Galdeano, al que hemos localizado como socio de este Círculo ${ }^{79}$. Las colecciones de estas publicaciones, además, estaban bastante completas, lo que evidencia que había un grupo de socios que eran lectores habituales de ellas, algo que el directivo responsable de la biblioteca tendría en cuenta a la hora de proponer su continuidad o la cancelación de la suscripción.

79. Residió temporalmente en Valladolid por razones profesionales. Su corresponsal en la ciudad era Jorge Montero. Véase Maryse Villapadierna, "José Lázaro Galdeano (1862-1947) et La España Moderna (1889-1914), ou une entreprise culturelle et ses implications économiques et commerciales», en C. Dumas, Culture et société en Espagne et en Amérique latine au XIXe siècle, Université de Lille, 1980, pp. 93-102. Sobre su caracterización como intermediario cultural: Jean-François Botrel, «Passeurs culturels en Espagne (1875-1914)», en D. Cooper-Richet, J.-Y. Mollier y A. Silem, Dirs., Passeurs culturels dans le monde des médias et de l'édition en Europe (XIXe et XXe siècles), op. cit., pp. 209-228. 


\section{CONSIDERACIONES FinALES}

Es obvio que en el Círculo existían varios niveles de lectura, que se correspondían con otros tantos usos diferenciados del gabinete de lectura y de la biblioteca. Lo que sin duda predominaba era el lector del periódico diario, un uso que sería dudoso asociar a la posesión de unos intereses culturales elevados, más bien, incluso, se podría pensar en lo contrario, en una proclividad a la trivialización y a la simplificación, signos de una mediocridad burguesa que, en otro contexto se condensaría bien en personajes literarios como el de monsieur Bamatabois, de Les misérables, de Víctor Hugo ${ }^{80}$. Las opiniones de Baudelaire o de Rémusat con respecto a los cercles franceses, tanto de París como de provincias, y que serían probablemente aplicables a los espańoles, se orientan por esa segunda alternativa, poniendo en relación, incluso, en el caso de Rémusat, el desprecio por los libros con la fácil y rápida información obtenida de los periódicos, que dispensarían de estudios y reflexiones para adquirir las luces del siglo ${ }^{81}$. Y eso sería sintomático de la inferioridad cultural de la sociabilidad burguesa, respecto de la aristocrática de los salones. Ciertamente, las opiniones que hemos aportado al comienzo de este artículo de autores como Unamuno, Clarín, Pla, parecen confirmar que la polarización en la lectura de la prensa diaria iba relacionada con una mediocridad cultural bastante extendida entre los miembros de estas sociedades.

En el otro extremo se situaría el lector de libros, un vehículo de lectura al que habría que diferenciar del periódico diario, pero también de ciertas revistas $^{82}$, pues exigía una dedicación y una relación íntima con el texto, sobre todo en el caso de la lectura silenciosa ${ }^{83}$, que no es fácil se diera en el caso de la prensa, más propicia al comentario en alta $v z^{84}$ y a una lectura más superficial y efímera, que parece pudo acentuarse en el último tercio del siglo XIX, con la irrupción de la prensa de información general ${ }^{85}$. No tenemos

80. Cabe remitir a Maurice Agulhon, «Reflexiones sobre la imagen del burgués francés en vísperas de 1848: Monsieur Prudhomme, Monsieur Homais y Monsieur Bamatabois», en Historia Social, 29, 1997, pp. 73-87.

81. Véase Maurice Agulhon, El Círculo burgués. La sociabilidad en Francia, 1810-1848, Avellaneda, Siglo XXI, 2009, pp. 142-144, ed. de Pilar González Bernardo.

82. Michel Leymarie, «Introduction. La belle époque des revues?», en J. Pluet-Despatin, M. Leymarie y J.-Y. Mollier, Dirs., La belle époque des revues, 1880-1914, op. cit., pp. 11-12.

83. Jesús A. Martínez Martín, «La lectura en la España contemporánea: lectores, discursos y prácticas de lectura», en Ayer, 58 (2005(2), p. 27 y ss.

84. En el primer reglamento de la Entidad, y en relación con la prohibición, en el art. 44, de toda conversación que versara sobre política, se prevenía sobre que, «bajo cualquier punto de vista puedan los socios hacer comentario alguno acerca de las noticias que en este sentido inserten los periódicos», lo que parece confirmar que tales comentarios eran moneda corriente: Reglamento del Círculo de Valladolid, Valladolid, Imprenta de la Sra. Viuda de Roldán, 1844, p. 12.

85. Jesús A. Martínez Martín, «La circulación de los libros y la socialización de la lectura. Nuevos públicos y nuevas prácticas», en J. A. Martínez Martín (dir.), Historia de la edición en España (1836-1936), op. cit., 466-467. 
prácticamente testimonios, salvo el que se aportará en seguida, de ese segundo tipo de prácticas lectoras en el Círculo, y además, discriminar el (no nos cabe duda que) pequeño grupo o minoría de lectores de libros, que coincidirían en ciertos casos con los interesados en las revistas científicas, literarias o de pensamiento, tiene mucho de especulativo. En todo caso conviene tener en cuenta, para entender mejor la función que pudieron desempeñar bibliotecas como esta, el carácter enteco de la lectura pública en España aproximadamente por las fechas en que se confeccionó este Indice ${ }^{86}$, pese a que en una ciudad como Valladolid esto pudiera en parte verse compensado por la existencia de una biblioteca universitaria relativamente bien dotada, no así la de un ateneo ya que su fundación se pospuso a $1909^{87}$.

Habría que pensar, también, que la biblioteca del Círculo, además de contribuir a satisfacer las inquietudes intelectuales o literarias de ciertos grupos de socios, pudo desempeñar un papel relevante de cara a la preparación de oposiciones, la puesta al día en determinados campos profesionales, la consulta de revistas especializadas o de anuarios jurídicos, etc. Y no hay que olvidar que la entidad contaba con un importante volumen de socios de carácter temporal, como funcionarios y militares, cuyas aficiones lectoras podían colmarse de modo fácil y económico recurriendo a los fondos literarios del Círculo. Aunque quizás la imagen más tópica del socio de estas entidades sea la del propietario rentista, que mataba el tiempo jugando, conversando o leyendo la prensa diaria, era también muy destacada la del profesional de clase media o el estudiante al que la biblioteca podía prestar importantes servicios. Hay un testimonio significativo de Francisco de Cossío que subraya esos otros usos de los espacios de lectura del Círculo:

Mi tío Manuel me hizo socio del Casino. El Círculo de la Victoria, muy restringido entonces, era el que reunía a las personas más distinguidas de la ciudad. Tenía un gran salón con chimeneas, una biblioteca muy buena, un billar, un saloncito donde nos reuníamos los muchachos, y una sala de juego donde se cultivaba el bacarrá y donde me estaba prohibido entrar [...] El tono de este círculo lo demuestra el tener correspondencia con los clubs de primera categoría de París (...) Pasé, sin embargo muchas horas en la biblioteca de este casino, en la que había unos sillones de cuero que invitaban a la lectura, y en la que compraban todas las novedades españolas y extranjeras. Esto, no obstante, mis novelistas favoritos eran los franceses... ${ }^{88}$

86. Jean-François Botrel, «Lectura y bibliotecas», en V. García de la Concha, Dir., Historia de la literatura española. Siglo XIX (I), coord. por G. Carnero, Madrid, Espasa Calpe, 1997, p. 22. Debe consultarse asimismo: Ana Martínez Rus, «Las bibliotecas y la lectura. De la biblioteca popular a la biblioteca pública», en J. A. Martínez Martín (dir.), Historia de la edición en España (1836-1936), op. cit., pp. 431-454.

87. Es cierto que, previamente, en 1872, hubo un primer ensayo de fundación del mismo, pero no llegó a consolidarse: José Luis Sánchez, La voluntad regeneracionista. Esfuerzo e inercia del Ateneo vallisoletano, 1872-1936, Valladolid, Región Editores, 1998.

88. Francisco de Cossío, Confesiones. Mi familia, mis amigos y mi época, Madrid, EspasaCalpe, 1959, p. 82. 
De cara a identificar posibles usuarios de la biblioteca conviene recordar cómo durante la Restauración pertenecieron al Círculo individualidades destacadas en el terreno intelectual como el krausoinstitucionista e historiador del derecho, Rafael Ureña, el que fuera efímero ministro republicano, José Muro López, que había sido discípulo de Sanz del Río en la Universidad Central, el propio José Lázaro Galdiano, como se ha apuntado, los historiadores Juan Ortega Rubio y Claudio Sánchez Albornoz ${ }^{89}$, así como una serie de escritores y eruditos, en parte ya citados, que se dieron a conocer en el siglo $\mathrm{XX}^{90}$, entre los que descollaría la presencia del poeta Jorge Guillén. No hay que olvidar, en fin, que buena parte del comité directivo en Valladolid de la Agrupación al servicio de la República (comenzando por su presidente, Narciso Alonso Cortés), estuvo formada por socios del Círculo de Recreo ${ }^{91}$.

Una reflexión final, más específica, merecen los posibles lectores de ese grupo de revistas de pensamiento, de alta divulgación científica que se recibían en la entidad y que, en su misma concepción implicaban la existencia de unas redes potenciales de lectura que estarían formadas en este caso por socios provistos de un fuerte capital escolar (profesionales liberales, universitarios, docentes, ingenieros, entre otros), así como una cierta comunidad de ideas entre editores y lectores, más proclives a convertirse en rehenes o cautivos de las políticas de los primeros ${ }^{92}$, lo mismo que ocurría, seguramente, con las colecciones.

89. Algunas referencias a su pertenencia al Casino en: Claudio Sánchez-Albornoz y Menduiña, Mis tres primeros estudios históricos (Iniciación de una vocación), Valladolid, Universidad de Valladolid, 1974, p. 9.

90. Lorenzo Rubio González, La literatura en Valladolid en el siglo XX (1900-1939), Valladolid, Ateneo de Valladolid, 1989.

91. La composición de la Agrupación en Jesús María Palomares Ibáñez, La Segunda República en Valladolid. Agrupaciones y partidos politicos, Valladolid, Universidad de Valladolid, 1996, pp. 25-29.

92. Véase Jean-Yves Mollier, «La revue dans le système editorial», en J. Pluet-Despatin, M. Leymarie y J.-Y. Mollier, Dirs., La belle époque des revues, 1880-1914, op. cit., p. 50. 